\title{
Epidemiological Study of Vitiligo in Damanhour Teaching Hospital
}

\author{
Ihab Y. Abdallah, Osama Hussein, Amany A. Abdelmagid
}

\begin{abstract}
Department of Dermatology and Andrology, Faculty of Medicine, Benha University Egypt,
\end{abstract}

Correspondence to: Amany A. Abdelmagid, ddepartment of Dermatology and Andrology, Faculty of Medicine, Benha University, Egypt.

Email:

nany_89_2009@yahoo.com

Available online: 14 May 2020

\section{Abstract:}

Background: Vitiligo is the most common skin depigmenting disorder resulting from a selective loss of epidermal melanocytes, and affects around $0.5 \%$ of the world population. Both sexes are affected, and there are no apparent differences in rates of occurrence according to phototype or race. Aims: This study was done to evaluate the epidemiology of vitiligo in Damanhour teaching hospital and to assess the clinical presentations of vitiligo. Patients and methods : This is a cross-sectional study on patients of vitiligo among cases who attended the dermatology and andrology outpatient clinic in Damanhour teaching hospital ,El-Behira ,Egypt .A predesigned dermatological sheet was used for data collection from the first 10,000 patients during a period of six months. Patients were clinically examined to determine type of skin diseases they have and those with vitiligo were selected. Results : Out of 10,000 studied patients, there were 86 cases of vitiligo with a prevalence of $0.86 \%$. The results revealed a female predominance. There was a predominance of patients from rural areas. The most common associated disorder was thyroid disease. Conclusion: the prevalence of vitilgo in Damanhour teaching hospital is $0.86 \%$ and it is slightly more common among females and in rural areas. The most common exacerbating factor is stress.

Keywords : Vitiligo ,epidemiology ,associated diseases , Egypt.

\section{Introduction}

Vitiligo is the most common skin depigmenting disorder resulting from a selective loss of epidermal melanocytes, and affects around $0.5 \%$ of the world population
[1]. Both sexes are equally affected, and there are no apparent differences in rates of occurrence according to phototype or race. Twenty-five percent of cases are children with disease onset before the age of 10 , the age of onset in pediatric series varies from 4 to 
8 years. Very early onset, as young as 3 months, is acknowledged. The existence of true 'congenital vitiligo' remains controversial. The prevalence of segmental vitiligo in childhood varies from 4.6 to $32.5 \%$ in published reports [2].

In fair-skinned individuals, vitiligo patches are usually detected only after the first exposure of the skin to sunlight, following the first summer of life. The percentage of segmental vitiligo (SV) is higher in children compared to adults, whatever the ethnic background, suggesting a mosaic skin developmental predisposition [1].

A major role of silent inflammation and autoimmunity is demonstrable, in particular during the progressive phase of the disease. Since neither immune nor non-immune mechanisms can sufficiently explain all parts of this complex disease, a convergence of combined biochemical, environmental, and immunological factors in genetically predisposed patients has been proposed as a unifying background to the pathophysiology of vitiligo [3].

Common genetic variants associated with the disease have been identified, and provide insights into biological pathways and reveal possible novel drug targets. Some rare family trees show an impressive aggregation of cases of vitiligo and auto-immune disorders, and may justify a more comprehensive autoimmune screen. Consanguinity is clearly a risk factor, as shown in Middle East studies [4].

Vitiligo has an unpredictable disease course. In the absence of a biomarker, clinical signs of disease activity can be used to help clinicians determine prognosis and guide treatment. For these patients, physicians may consider taking a more aggressive therapeutic approach with treatment, such as increasing the potency of topical agents applied to lesions, increasing the frequency of phototherapy and the use of systemic corticosteroids [5].

Diagnosis of vitiligo is usually clinical. Wood's lamp examination helps to distinguish hypopigmented from depigmented macules. Biopsy is usually not necessary unless other differentials such as morphea or lichen sclerosus are suspected [6].

Multiple therapies, including topical agents, light therapies, and autologous grafting procedures, have demonstrated efficacy for repigmentation of vitiligo [7].

\section{Patients and methods:}

This cross-sectional study was carried out on patients with vitiligo attending the dermatology and andrology outpatient clinic in Damnhour teaching hospital, El-Beheira in a period of 6 months. 


\section{Methods:}

The ethical committee and dermatology and andrology department of Benha faculty of medicine approved the study. An informed consent was obtained from all patients. It included all details about the study (title, objectives, methods, expected benefits and confidentiality data).

The aim of the study was explained to the patients before taking their informed consent. The vitiligo patients were subjected to a detailed medical history including personal, present, past and family history then general and local examination by the investigating doctor.

Vitiligo patients were selected from the first 10,000 patients attending the dermatology clinic in Damnhour teahing hospital during a period of six months starting November 2017. Data was collected using a predesigned dermatological sheet which is used for data collection.

\section{Data management:}

The clinical data were recorded on a report form. These data were tabulated and analyzed using the computer program SPSS (Statistical package for social science) version 20 to omit:

Descriptive statistics were calculated for the data in the form of frequency and distribution for qualitative data.
In the statistical comparison between the distinct groups, the significance of difference was tested using one of the following tests: -

Inter-group comparison of categorical data was performed by using chi square test $\left(X^{2}\right.$ value) and fisher exact test (FET).

A $P$ value $<0.05$ was considered statistically significant $\left(^{*}\right)$ while $>0.05$ statistically insignificant and $p$ value $<0.01$ was considered highly significant $(* *)$ in all analysis.

\section{Results}

Among 10000 cases examined during a period of 6 months, 86 patients had vitiligo. Thus the prevalence of Vitiligo in Damnhour teaching hospital was $0.86 \%$.

Table 1. Demographic data of studied group.

Table 1 shows that among 86 patients complaining of vitiligo ,the female patients were $54(62.8 \%)$, and the male patients were 32 (37.2\%).The commonest age group affected was 10-19 years old group (27.9\%). Also, most patients $(88.4 \%)$ lived in rural areas.

Table 2 . Factors affecting the course of the disease in studied group.

Table 2 shows that the more common excerbating factors were trauma in 18 cases (20.9\%) and stress in 20 cases (23.3). Vitiligo affected work in 8 cases $(9.3 \%)$. 
Table 3 . Family history of studied group.

Table 3 shows that family history of studied group of similar condition was positive in 10 cases(11.6\%). Past history of other dermatological diseases was present in some cases .It was positive with atopic eczema in 2 cases $(2.3 \%)$, psoriasis in 4 cases $(4.7 \%)$ and none in 80 cases(93\%). Past history of general diseases included diabetes mellitus in 8 cases (9.3\%), thyroid disease in 4 cases $(4.7 \%)$, hypertension in 8 cases $(9.3 \%)$, hepatitis in 4 cases $(4.7 \%)$ and none in 62 cases $(72.1 \%)$.

Table 1: demographic data of studied group:

\begin{tabular}{|c|c|c|c|}
\hline \multicolumn{2}{|c|}{$(\mathrm{n}=86)$} & $\mathbf{N}$ & $\%$ \\
\hline \multirow{2}{*}{ Sex } & Male & 32 & 37.2 \\
\hline & Female & 54 & 62.8 \\
\hline \multirow{5}{*}{ Age (years) } & $<10$ & 14 & 16.3 \\
\hline & $10-19$ & 24 & 27.9 \\
\hline & $20-29$ & 20 & 23.3 \\
\hline & $30-49$ & 14 & 16.3 \\
\hline & $50+$ & 14 & 16.3 \\
\hline \multirow{5}{*}{ Occupation } & Worker & 6 & 7.0 \\
\hline & Student & 22 & 25.6 \\
\hline & Employee & 30 & 34.9 \\
\hline & Farmer & 8 & 9.3 \\
\hline & Not working & 20 & 23.3 \\
\hline \multirow{2}{*}{ Residence } & Urban & 10 & 11.6 \\
\hline & Rural & 76 & 88.4 \\
\hline
\end{tabular}

Table 2: Factors affecting the course of the disease in studied group.

\begin{tabular}{lcc}
\hline $\begin{array}{l}\text { Variant } \\
(\mathbf{n}=\mathbf{8 6})\end{array}$ & $\mathbf{N}$ & $\mathbf{\%}$ \\
\hline Exacerbating factors & 18 & 20.9 \\
Trauma & 2 & 2.3 \\
Cold & 20 & 23.3 \\
Stress & 46 & 53.5 \\
None & 8 & 9.3 \\
Occupational factors & & \\
It affects work & 78 & 90.7 \\
No &
\end{tabular}

Table 3: Family history of studied group.

\begin{tabular}{llcc}
\hline $\begin{array}{l}\text { Variant } \\
(\mathbf{n = 8 6})\end{array}$ & & $\mathbf{n}$ & $\boldsymbol{\%}$ \\
\hline $\begin{array}{l}\text { Of similar } \\
\text { condition }\end{array}$ & Yes & 10 & 11.6 \\
& No & 76 & 88.4 \\
$\begin{array}{l}\text { Of other } \\
\text { dermatological } \\
\text { problems }\end{array}$ & Psopiasis eczema & 2 & 2.3 \\
& None & 4 & 4.7 \\
& Diabetes mellitus & 8 & 9.3 \\
& Hypertension & 8 & 9.3 \\
$\begin{array}{l}\text { Of general } \\
\text { diseases }\end{array}$ & Thyroid disease & 4 & 4.7 \\
& Hepatitis & 4 & 4.7 \\
& None & 62 & 72.1 \\
\hline
\end{tabular}




\section{Discussion}

Some previous reports that were done on the epidemiology of vitiligo were based on population surveys, while others were performed in patients of dermatology clinics. However, the prevalence of vitiligo varies in different geographic regions and different sample size, and the data have limitations and localizations. Besides, the disorder afflicts various ethnic populations with varying prevalence estimates ranging from $0.1 \%$ to $2 \%$ based on the general populations in previous study [8] .

This study showed that there was a predominance of patients from rural areas $(88.4 \%)$. This could be explained in this study by the fact that most people in El-Beheira, the area of study, live in rural areas. This is in agreement with another study in Egypt[9].On the other hand another study in China reported no difference in prevalence between rural and urban areas[10].

In the current study the prevalence of vitiligo was $0.86 \%$ while the prevalence of vitiligo in another Egyptian study was $1.22 \%$ between the years 1994 to 1996 in all age groups [11].Also, in another Egyptian study , the prevalence was $0.18 \%$ [12], that study enrolled patients with vitiligo aged $\leq 18$ in 2008 to 2009 . The prevalence was $0.06 \%$ in an Egyptian study which was performed in
2011 2012 in patients with age group 6 12 years[9].

In the current study there was a female predominance, the female patients with vitiligo were $54(62.8 \%)$ and male patients were $32(37.2 \%)$. This was in agreement with other studies like a Roman study that included 10,040 vitiligo patients and, 5457 were females $(54.4 \%)$ [13].Also, a review of 1010 patients from a Gujarat, India dermatology clinic identified a female predominance of $57.3 \%$ [14]. Women usually worry more about pigmentation changes of their skin and these changes usually affect their social life. This could be a possible reason for the female predominance in this study.

The most common age group in our study was those between age 10 to 29 years (51.2\%).This nearly corresponds to other studies like a study from Rome that showed that $63.9 \%$ of patients were under the age of 40 [13]. Also a review of 1010 patients in India showed that most cases had onset by age of 30 years and only $4.3 \%$ had onset after the age of 60 years [14].It may be underestimation of geriatric patients because of their poor general conditions and their restricted mobility.

On the other hand a study in Korea reported bimodal distribution of peaks at age 5 to 15 years $(16.05 \%)$ and 45 to 55 years $(16.5 \%)$ 
[15] while a study in Taiwan reported the age of onset was 40-59 years old [16].

In this study the more affected site was head in females and neck in males which is identical to a study in a pediatric cohort from Chicago,where head and neck involvement was the most common site in $36.5 \%$ of cases [17]. Also a cohort of Korean children had head and neck involvement in $58.8 \%$ confirming that this was the leading site of disease for children [18].

In the present study exacerbating factors were trauma in 18 cases $(20.9 \%)$. This is in agreement with a study in India which reported that koebner phenomenon was found in $20.8-31.3 \%$ among patients with vitiligo [14]. While a study in Turkey reported that it was seen in a small group (7.5-11.48 \%) [19].

In the current study vitiligo affected work in 8 cases $(9.3 \%)$. Another study reported that disease severity and psychological fallout had not been found strongly associated [20].Vitiligo requires ongoing psychosocial support. There is a strong need for a psychoeducational intervention with focus on acceptance and managing social impact [21].

In the current study family history was found in $11.6 \%$.It corresponds nearly to a Chinese survey of 815 probands that reported family history in $15.7 \%$ [22].Vitiligo could be an inheritable disease, as stated by a study in the
Qassim Region of Saudi Arabia of 111 vitiligo patients (61 males; 50 females) demonstrated consanguinity in $32.4 \%$ of cases and first-degree cousin consanguinity in $22.5 \%$ of cases. Consanguineous cases had an earlier age of onset [23].

In the present study a past history of vitiligo was positive in 30 cases (34.9\%).Past history of other dermatological diseases included atopic eczema in 2 cases (2.3\%), alopecia areata in 4 cases $(4.7 \%)$.On the other hand in an Indian cohort, patients had comorbid alopecia areata in $1.9 \%$,psoriasis in $0.4 \%$, and atopic dermatitis in $1 \%$ [24].

In the present study thyroid disease was positive in 6 cases (7\%).This corresponds nearly to a study in Tabriz, Iran that reported thyroid disease three times more common in vitiligo patients than in the control group $(p=0.008)$ [24].Autoimmune thyroid disease is the most frequent autoimmune disorder associated with vitiligo [25]. The prevalence of vitiligo has been shown to fluctuate between $2.7 \%$ to $7 \%$ among autoimmune thyroid patients [26].Vitiligo may be an autoimmune disease so could be associated with other autoimmune diseases.

In our study combination therapies of NBUVB and vitamin D analogs were better than NB-UVB alone .These results are in agreement with other study [27]. 


\section{Limitations}

Many items in this study like family history, exacerbating and alleviating factors and age of onset of vitiligo depend only upon history taking from the patient.

Some patients declined to participate in the study so prevalence data may suffer from mild participation bias.

Diagnosis was carried out only on a clinical basis and this study was done over a short period of 6 months only.

\section{Conclusion}

In conclusion, the prevalence of vitilgo in Damanhour teaching hospital was $0.86 \%$ according to this study and it was slightly more common among females and in rural areas. The most exacerbating factor was stress and the most common associated disorder was thyroid disease.

\section{References}

1. Picardo M, Dell'Anna ML, Ezzedine K. Vitiligo. Nat Rev Dis Primer. 2015 ; 4;1:15011

2. Taïeb A, Seneschal J, Mazereeuw-Hautier J.Special considerations in children with vitiligo. Dermatol Clin.2017; 35:229-233.

3. Bertolotti A, Boniface K, Vergier B, Mossalayi D, Taieb A, Ezzedine K, Seneschal J. Type I interferon signature in the initiation of the immune response in vitiligo. Pigment Cell Melanoma Res. $2014 ; 27(3): 398-407$.

4. Jin Y, Andersen G, Yorgov D, Ferrara TM, Ben S, Brownson $\mathrm{KM}$ et al.Genome-wide association studies of autoimmune vitiligo identify 23 new risk loci and highlight key pathways and regulatory variants. Nat Genet . 2016 ;48:14181424.

5. Aboul-Fettouh N, Hinojosa J, Tovar-Garza A, Pandya AG. The majority of patients presenting with vitiligo have a clinical sign of activity. J Am Acad Dermatol. 2017 ; 31;77(4):774-5.

6. Mostaghimi L .Vitiligo. In: França K , Jafferany M (eds) .Stress and Skin Disorders. Springer, Cham . 2017. pp 127-135.

7. Whitton M, Pinart M, Batchelor JM, Leonardi-Bee J, Gonzalez U, Jiyad Z, Eleftheriadou V, Ezzedine K. Evidence-based management of vitiligo: summary of a Cochrane systematic review. Br J Dermatol. 2016;174(5):962-9.

8. Zhang Y, Cai Y, Shi M, Jiang S, Cui S, Wu Y, Gao XH, Chen HD. The prevalence of vitiligo: a meta-analysis. PloS one. 2016 ;27;11(9):e0163806.

9. El-Khateeb EA, Lotfi RA, Abdel-Aziz KM, ElShiekh SE. Prevalences of skin diseases among primary school children in Damietta, Egypt. Int $\mathbf{J}$ Dermatol. 2014;53(5):609-16.

10.Lu T, Gao T, Wang A, Jin Y, Li Q, Li C. Vitiligo prevalence study in Shaanxi province, China. Int $\mathrm{J}$ Dermatol. 2007;46(1):47-51.

11. Abdel-Hafez K, Abdel-Aty MA, Hofny ER. Prevalence of skin diseases in rural areas of Assiut Governorate, Upper Egypt. Int J Dermatol. 2003 ;42(11):887-92.

12. Yamamah GA, Emam HM, Abdelhamid MF, Elsaie ML, Shehata H, Farid T, Kamel MI, Taalat AA. Epidemiologic study of dermatologic disorders among children in South Sinai, Egypt. Int J Dermatol. 2012 ;51(10):1180-5.

13. Paradisi A, Tabolli S, Didona B, Sobrino L, Russo $\mathrm{N}$, Abeni D. Markedly reduced incidence of melanoma and nonmelanoma skin cancer in a nonconcurrent cohort of 10,040 patients with vitiligo. J Am Acad Dermatol. 2014 ;1;71(6):11106.

14. Vora RV, Patel BB, Chaudhary AH, Mehta MJ, Pilani AP. A clinical study of vitiligo in a rural set up of Gujarat. Ind J Comm Med. 2014;39(3):143.

15.Lee H, Lee MH, Lee DY, Kang HY, Kim KH, Choi GS, Shin J, Lee HJ, Kim DH, Kim TH, Lee AY. Prevalence of vitiligo and associated comorbidities in Korea. Yonsei Med J. 2015 ;1;56(3):719-25.

16. Chen YT, Chen YJ, Hwang CY, Lin MW, Chen TJ, Chen CC, Chu SY, Lee DD, Chang YT, Liu HN. Comorbidity profiles in association with vitiligo: a nationwide population-based study in Taiwan. J Eur Acad Dermatol Venereol . 2015 ;29(7):1362-9.

17. Pajvani U, Ahmad N, Wiley A, Levy RM, Kundu R, Mancini AJ, Chamlin S, Wagner A, Paller AS. 
The relationship between family medical history and childhood vitiligo. . J Am Acad Dermatol. $2006 ; 1 ; 55(2): 238-44$.

18. Cho S, Kang HC, Hahm JH. Characteristics of vitiligo in Korean children. Pediatr Dermatol. 2000;17(3):189-93.

19. Kalkanli ${ }^{1}$ N, Kalkanli S. Classification and comperative study of vitiligo in Southeast of Turkey with biochemical and immunological parameters. Clin Ter. 2013;164(5):397-402.

20. Bonotis K, Pantelis K, Karaoulanis S, Katsimaglis C, Papaliaga M, Zafiriou E, Tsogas $\mathrm{P}$. Investigation of factors associated with healthrelated quality of life and psychological distress in vitiligo. J Dtsch Dermatol Ges.2016;14(1):45-9.

21. Ahmed A, Steed L, Burden-The E, Shah R, Sanyal S, Tour S, Dowey S, Whitton M, Batchelor J.M , Bewley A.P. Identifying key components for a psychological intervention for people with vitiligo-a quantitative and qualitative study in the United Kingdom using web-based questionnaires of people with vitiligo and healthcare professionals. J Eur Acad Dermatol Venereol. 2018 (4):1-20.

22.Sun X, Xu A, Wei X, Ouyang J, Lu L, Chen M, Zhang D. Genetic epidemiology of vitiligo: a study of 815 probands and their families from south China. . Int J Dermatol. 2006;45(10):1176-81.
23. Alzolibani A. Genetic epidemiology and heritability of vitiligo in the Qassim region of Saudi Arabia. Acta Dermatovenerol Alp Panonica Adriat. 2009;18(3):119-25.

24. Nejad SB, Qadim HH, Nazeman L, Fadaii R, Goldust M. Frequency of autoimmune diseases in those suffering from vitiligo in comparison with normal population. Pak J Biol Sci. 2013, 15;16(12):570-4.

25. Gill L, Zarbo A, Isedeh P, Jacobsen G, Lim HW, Hamzavi I. Comorbid autoimmune diseases in patients with vitiligo: a cross-sectional study. J Am Acad Dermatol .2016 1;74(2):295-302.

26. Ruggeri RM, Trimarchi F, Giuffrida G, Certo R, Cama E, Campennì A, Alibrandi A, De Luca F, Wasniewska M. Autoimmune comorbidities in Hashimoto's thyroiditis: different patterns of association in adulthood and childhood/adolescence. .Eur J Endocrinol. 2017, 1;176(2):133-41.

27. Whitton ME, Pinart M, Batchelor J, Leonardi-Bee J, Gonzalez U, Jiyad Z, Eleftheriadou V, Ezzedine $\mathrm{K}$.Interventions for vitiligo. Cochrane Database Syst Rev.2015 , (2):CD003263.

To cite this article: Ihab Y. Abdallah , Osama Hussein , Amany A. Abdelmagid. Epidemiological Study of Vitiligo n Damanhour Teaching Hospital. BMFJ 2020;37(1):297304. 